\title{
Comments on Trachtman et al.: Recurrent focal segmental glomerulosclerosis after kidney transplantation
}

\author{
Caroline Straatmann $^{1} \cdot$ V. Matti Vehaskari ${ }^{1}$
}

Received: 1 October 2015 / Accepted: 2 October 2015 / Published online: 3 March 2016

(C) IPNA 2016

Dear Editor,

We are writing in reference to the Educational Review article by Trachtman et al. entitled "Recurrent focal segmental glomerulosclerosis after kidney transplantation", recently published in the October 2015 issue of Pediatric Nephrology [1]. The text referencing our cited article [2] is erroneous. It states "Straatmann et al. [2] documented that plasmapheresis without concomitant use of immunosuppressive drugs was effective in treating seven out of 29 patients with FSGS who received a kidney transplant and who developed recurrent disease." This wording suggests that only 7/29 patients had a successful course with plasmapheresis; however, we had a $100 \%$ success rate in $7 / 7$ patients. We performed retrospective chart review on 24 patients who received transplants for FSGS from 1995 to 2013. Among those 24 patients (not 29 as stated), 7 had FSGS recurrence (29\%.) Our early and intensive use of plasmapheresis to treat recurrent FSGS was universally successful, and 7/7 patients have had a complete and sustained remission with a mean follow-up period of 4.5 years. We published our results with plasmapheresis in an unselected, consecutive, strictly pediatric cohort of patients with biopsy-proven recurrent disease. We started plasmapheresis promptly, and some patients did require prolonged plasmapheresis courses (up to 6 months), with the duration guided by the urine protein to creatinine ratio. No additional immunosuppression was used in 4 of the 7 treated patients. We feel that our study provides convincing and timely evidence for prompt and potentially prolonged use of plasmapheresis as a successful treatment for recurrent FSGS.

\section{References}

1. Trachtman R, Sran SS, Trachtman H (2015) Recurrent focal segmental glomerulosclerosis after kidney transplantation. Pediatr Nephrol 30:1793-1802

2. Straatmann C, Kallash M, Killackey M, Iorember F, Aviles D, Bamgbola O, Carson T, Florman S, Vehaskari MV (2014) Success with plasmapheresis treatment for recurrent focal segmental glomerulosclerosis in pediatric renal transplant recipients. Pediatr Transplant 18(1):29-34
A reply to these comments can be found at doi:10.1007/s00467-0153250-z.

\footnotetext{
Caroline Straatmann

cstraa@1suhsc.edu

1 Louisiana State University Health Sciences Center, New Orleans, LA, USA
} 